\title{
Esbozo de la evolución del derecho romano*
}

\section{Salvatore Riccobono*}

Resumen. Desde una novedosa perspectiva de estudios romanísticos propia de la primera mitad del siglo xx, en este artículo el eminente romanista Salvatore Riccobono nos ilustra de manera magistral con su método crítico sobre los grandes momentos y desarrollos del sistema jurídico romanístico, para concluir que el Corpus Iuris de Justiniano fue el producto de la tradición del derecho romano y no de la influencia helenística. Los tres elementos jurídicos propios de la tradición romanística: ius civile, ius honorarium, ius gentium, se destacan en su relación con los juristas, la tarea de la jurisprudencia romana, y la actividad del pretor basada en la equidad. Es grato presentar esta traducción casi un siglo después.

PALABRAS ClAVE: derecho romano, historia del derecho, tradición romanística, tradición jurídica occidental

* Fecha de recepción: 6 de julio de 2020. Fecha de aceptación: 28 de agosto de 2020.

Para citar el artículo: Riccobono, S., "Esbozo de la evolución del derecho romano", Revista de Derecho Privado, Universidad Externado de Colombia, n. ${ }^{\circ} 40$, enero-junio 2021, 497-512, DOI: https://doi.org/10.18601/01234366.n40.17.

Originalmente publicado en inglés: Riccobono, S., "Outlines of the evolution of Roman Law", 74 U.Pa.L. Rev. 1 (1925). Todos los derechos pertenecen a la University of Pennsylvania Law Review, que autorizó la traducción al español pero no participó en ella, ni revisó la versión final.

Trad. del inglés: José Félix Chamie.

** Salvatore Riccobono (1864-1958) fue un destacado jurista y académico italiano, uno de los más insignes romanistas de su tiempo, profesor de derecho romano en numerosas universidades como las de Palermo, Sassari, Camerino, Roma, Oxford y Washington; doctor honoris causa por las universidades de Oxford, Vilna, Gotinga y Washington. 


\title{
Outlines of the Evolution of Roman Law
}

\begin{abstract}
In this article, the eminent Romanist Salvatore Riccobono masterfully illustrates, from a perspective of Romanistic studies typical of the first half of the 20th century, about the great moments and developments of the Roman law legal system tradition, to conclude that Justinian's Corpus Iuris was the product of the tradition of Roman law and not of the Hellenistic influence. The three legal elements typical of the Roman law tradition: ius civile, ius honorarium, ius gentium, stand out in their relationship with jurists, the task of Roman jurisprudence, and the activity of the Praetor based on equity.
\end{abstract}

KeYwords: Roman Law, History of Law, Romanistic Tradition, Western Legal Tradition.

En una serie de trabajos publicados por mí durante los últimos quince años, me he esforzado por rastrear el desarrollo del derecho romano. Su curso puede mostrarse mejor gráficamente por diferentes líneas que, para el período que va de las XII Tablas a Diocleciano, divergen rápidamente y luego, de Constantino a Justiniano, se curvan hacia adentro y gradualmente convergen en una sola línea. Las líneas divergentes representan el floreciente período formativo del sistema jurídico romanístico; las líneas convergentes, el período de disminución o simplificación.

En la primera fase, el período formativo, o de la formación del sistema, el derecho se desarrolla en armonía con el creciente poder de Roma. Poco después de las Guerras Púnicas asume una forma más compleja. Posteriormente va a contener elementos o ramas jurídicas diversas que coexisten entre ellas, tanto en su aplicación como en su estructura intrínseca. Los elementos o ramas jurídicas que primero deben considerarse, aunque se desarrollan en períodos sucesivos, son los tres siguientes:

1. El ius civile, derecho personal de los ciudadanos romanos, que surgió de antiguas costumbres y que, por lo tanto, era estrecho, formal y estricto.

2. El ius gentium, derecho común de todos los hombres libres, fueran ciudadanos o extranjeros, y que, a diferencia del ius civile, no era formalista y estaba dominado por el principio de equidad.

3. El ius honorarium, que incorporaba varios precedentes, herramientas y recursos jurídicos adoptados por ciertos magistrados, en particular por el pretor, para facilitar la aplicación del ius civile, proporcionando lo que faltaba e incluso corrigiendo el derecho civil.

Esta rama del derecho (ius honorarium) fue la última en evolucionar, pero tuvo un crecimiento continuo hasta el reinado del emperador Adriano.

Cada año, el pretor, al asumir el cargo, decretaba en su programa (Edictum) cuáles actiones y, en este sentido, cuáles remedios precedentes reconocería durante su mandato. El edicto de los predecesores era objeto de modificaciones o adiciones 
sugeridas por la experiencia durante el curso de la magistratura. Así, el Edictum, teniendo en cuenta las necesidades de la vida cotidiana, mantuvo el ritmo del progreso social, económico y espiritual de la civilización romana.

Estos tres elementos o ramas del derecho aparecen bien delineados a medida que nos acercamos al final de la República, y ya en tiempos de Cicerón el ius honorarium se considera la fuente de derecho más grande y aparentemente líder.

Este es el significado de la frase que aparece en D. 1, 1,8 (Marciano 1 Institutionum): "Viva vox iuris civilis", que se refería al pretor, como también Aristóteles ${ }^{1}$

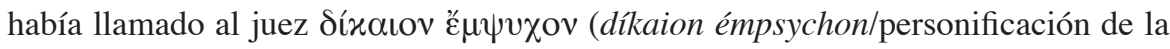
justicia) y Cicerón ${ }^{2}$ había llamado al magistrado "legem loquentem" (la ley que habla). Por lo tanto, el pretor, en su aplicación práctica del derecho, le da nueva vida al antiguo ius civile.

Desde Cicerón hasta Diocleciano, el desarrollo de la jurisprudencia se ocupó principalmente de la elaboración científica de los institutos y de la sistematización del derecho. Las diversas respuestas a las consultas (responsa), los juicios y las reglas de los antiguos fueron tratadas de tal manera que las leyes se rindieron a las exigencias de la vida cotidiana y a las ideas equitativas. La jurisprudencia desarrolló así un maravilloso análisis de los casos en los que se aplicaban los precedentes jurídicos. Con una perspicacia sorprendente, la jurisprudencia distinguió en los casos concretos los elementos psicológicos de lo extraño, lo ético de lo formal, lo histórico de lo práctico. Esto muestra y coordina, en diversas normas jurídicas, el valor y la función de la voluntad (mens animus), del acuerdo y de las consecuencias de los elementos del engaño y la buena fe (bona fides), abriendo así nuevas vías para el progreso del derecho.

Los resultados de dicho análisis realizado al aplicar el ius gentium, o el ius honorarium, también se extienden con frecuencia en la aplicación del ius civile. Así, en el período clásico, un elemento jurídico reacciona favorablemente sobre otro, y mediante un proceso de fusión crea realmente un sistema de derecho ${ }^{3}$.

Durante el Imperio, además de los tres elementos jurídicos citados anteriormente, surge un cuarto, que a veces se llama "ius novum". Este se compone de leyes, opiniones del Senado (senatusconsulta), constituciones o decretos del Emperador y, sobre todo, decisiones sobre asuntos referidos a varios magistrados que no estaban sujetos a las reglas ordinarias de ley (cognitio extra ordinem).

La tendencia general durante el Imperio es que el derecho estricto ceda a la equidad. Esto se logra de varias maneras: por ficciones, excepciones, construcciones legales, interpretaciones, analogías elaboradas por el pretor y por la jurisprudencia, así como por el Emperador.

1 Aristóteles, Ethica Nicomachea, v, 4,7 (1132).

2 Cicerón, M. T., De legibus, 3, 1, 2.

3 Véase también Bryce, J., Studies in History and Jurisprudence, Oxford University Press, vol. I, 1901, 97; vol. II, 291. 
Celso, el famoso jurista de la época del emperador Adriano, definió el derecho como sigue: "ius est ars boni et aequi", en una definición que reposa en D. 1, 1, 1. Ius, en esta definición, no puede referirse exclusivamente al ius civile, sino que cubre todo el complejo cuerpo de la ley. Sin embargo, Celso afirma que el ius es "un sistema de lo bueno y lo equitativo". Así, por fin se había realizado en el mundo romano lo que Cicerón había deseado tan ardientemente, sobre la base de los dictados de la filosofía aristotélica, y esto se dio, al menos, en aplicación práctica y propósito jurídico.

El ius honorarium funcionaba de manera idéntica a la central de energía eléctrica de la metrópoli moderna, que absorbe continuamente la energía inagotable que la naturaleza ofrece en diversas formas. Esta se transforma, almacena y finalmente se distribuye de acuerdo con las exigencias de la vida moderna. Por lo tanto, los requisitos de forma y el rigor y la restricción del ius civile no impidieron los resultados equitativos exigidos por el progreso de la vida civil.

El pretor es el árbitro del juicio. Para él, las normas jurídicas del ius civile no tienen ningún valor intrínseco. Lo que le preocupa es una base para la jurisdicción sobre la acción (actio) que se le presenta. Es decir, puede rechazar la jurisdicción, pero si la acepta, los jueces o aquellos que están designados para examinar el caso y pronunciar un juicio reciben una instrucción (formula) que establece las normas jurídicas que deben aplicarse en términos técnicos (formula in ius concepta), o que contiene una orden para condenar a la parte interesada cada vez que el hecho denunciado sea comprobado o admitido (formula in factum concepta).

Además, las normas de derecho utilizadas en los casos cubiertos por el ius civile también se pueden aplicar, mediante el uso de ficciones, a todos los casos no cubiertos por el ius civile y que a juicio del pretor tienen derecho a reparación (formulae fictitiae). Se ha dicho con acierto que el derecho romano no es un sistema de leyes, sino un sistema de acciones (actiones). Y las acciones, las pruebas y otros métodos de procedimiento regulares, perfeccionados o inventados por el pretor, se convirtieron en las características más admiradas del derecho romano debido a su variabilidad, precisión técnica y al extenso campo que cubrían. Este es el secreto del desarrollo continuo del derecho romano y la razón por la cual no se deterioró.

En particular, el sabio poder de dirección del pretor romano, como ya se ha dicho, explica el buen funcionamiento regular y fluido de los tres elementos jurídicos, que, cuando se consideran por separado, constituyen un sistema jurídico complicado y abstruso, debido a diferentes instrucciones con frecuencia contradictorias, y a normas de derecho en cada sistema. Algunos surgieron bajo la influencia de ideas y condiciones primitivas, y otros crecieron cuando el pensamiento humano y las condiciones fueron más avanzadas.

Hoy estamos bastante familiarizados con las normas de derecho y de procedimiento que prevalecieron desde Augusto hasta Diocleciano. Esto se debe principalmente a una pequeña obra del jurista Gayo, que vivió en el siglo il d.C., bajo Adriano. Este trabajo fue descubierto por el gran historiador Niehbur, en 1816, en un palimpsesto en la biblioteca de la catedral de Verona. 
El complejo sistema jurídico expuesto por Gayo permaneció inalterado hasta el reinado de Diocleciano. Al comparar el derecho entre la sistemática establecida por Gayo y la que fue codificada en el siglo vi d.C. por Justiniano, encontramos diferencias notables en todos los institutos, que a primera vista parecen ser apenas materiales. De hecho, todos los pasajes de Gayo y otros juristas citados por Justiniano en su obra se encuentran más o menos alterados. El emperador precisamente señala esto con las palabras: “... multa et maxima sunt quae propter utilitatem rerum transformata sunt" ${ }^{4}$ (muchas y muy importantes son las modificaciones introducidas por motivos de oportunidad).

Los estudios críticos llevados a cabo durante las últimas décadas, principalmente del Digesto, han confirmado ampliamente esta afirmación. Por lo tanto, el problema más grave del estudio del derecho romano es ahora el de investigar las causas que provocaron los cambios en el trabajo del legislador justinianeo. Durante el siglo XIX, los estudiosos consideraron que las distintas reformas hechas por Justiniano habían sido introducidas deliberadamente. Justiniano y sus colaboradores fueron reprendidos, criticados y denunciados por la profanación del monumento más notable del genio humano. Pero esta no fue otra cosa que una mera repetición de la actitud y el juicio de los comentaristas pertenecientes a las escuelas de Cujacio y Faber en el siglo Xvi, críticos de la obra de Justiniano.

A principios del siglo xx, el carácter de la acusación contra Justiniano cambió. Cuando se tuvo en cuenta la gran cantidad de interpolaciones, así como el breve período de tres años para llevar a cabo la compilación del Digesto, y las enmiendas que contradicen el derecho del período clásico, Justiniano fue considerado entonces un charlatán o un plagiario, en la medida en que se había atribuido a sí mismo el mérito de una obra que fue esencialmente el resultado de estudios y obras del siglo v d.C.

En cualquier caso, todos los cambios textuales y las diferencias de redacción se tomaron de digestos, glosas y compilaciones escolares hechas en Oriente durante los siglos anteriores. Esta opinión prevalece hoy en día entre los romanistas más jóvenes, a quienes se admira mucho por su gran entusiasmo en el estudio del Corpus Iuris. Sin embargo, parecen no comprender el maravilloso desarrollo de las doctrinas jurídicas y el trabajo de los juristas clásicos. Si bien es cierto que el emperador muestra su vanidad haciéndose pasar por un reformador del derecho, estas últimas acusaciones son de gran alcance y parecen haberse realizado sin un examen más profundo de la obra en sí.

Hoy se puede afirmar como un hecho seguro que el derecho romano sufrió cambios continuos desde la época de Constantino. Pero he sostenido y sigo sosteniendo que se modificó sin la ayuda y la cooperación de las escuelas de juristas, y que la legislación no brindó la asistencia adecuada en el proceso. El complicado sistema del derecho clásico se simplificó paso a paso en la práctica judicial. Los factores ex- 
ternos pueden haber estimulado y contribuido en el proceso de simplificación, pero esto se habría logrado en cualquier caso.

El ejemplo más llamativo de tal cambio es el uso de la escritura con fines legales, que gradualmente usurpó el lugar de las formas verbales solemnes del derecho romano clásico. El conflicto entre las formas escritas y verbales se manifestó en el siglo III d.C., después de la constitución de Antonino del año 212 d.C., por la cual el emperador extendió los privilegios de la ciudadanía romana a todos los habitantes del Imperio.

De hecho, hubiera sido increíble que la fórmula oral arcaica de la ley romana hubiese perdurado cuando el uso de la escritura había sido una costumbre característica en los países orientales donde se impuso el derecho romano.

El conflicto fue amargo durante el siglo III d.C., y es sorprendente la tenacidad con que Diocleciano todavía insiste en la observancia de las formas romanas. Desde los tiempos de Constantino, esta insistencia cesó, pero nunca hubo una regla general de que los instrumentos escritos fueran un sustituto de las formas orales romanas. Estas últimas fueron minimizadas, alteradas y finalmente desaparecieron por completo ya que habían persistido demasiado tiempo.

El cambio probablemente comenzó en la época de la República. Así, Cicerón considera el instrumento escrito (scriptura) como prueba absoluta en un juicio ${ }^{5}$. Además, el pretor a menudo consideraba que los requisitos orales solemnes se habían cumplido incluso cuando este no era el caso, permitiendo una acción ficticia (actio ficticia), con la fórmula atque si iure legitimo stipulatio interposita fuisset ${ }^{6}$ (lo mismo que si en legítima forma de derecho se hubiese interpuesto una estipulación), es decir, como si las formalidades requeridas por una estipulación se hubieran cumplido.

Al mismo tiempo que se admite la influencia de las costumbres orientales a este respecto, su importancia no debe exagerarse. Si Justiniano, en su elección entre la stipulatio del derecho civil y la obligatio litteris, que en sus últimas formas tenía un origen provincial ${ }^{7}$, dio preferencia a la stipulatio, que normalmente se hacía por escrito, esto significa que las instituciones jurídicas romanas mantenían su fuerza y atractivo incluso en el período bizantino a pesar de los cambios que sufrieron.

Pero las causas inmediatas y directas que generaron estos cambios se encuentran en las nuevas ordenanzas que fijaron la constitución política del Imperio y su organización administrativa y judicial según lo definido por Diocleciano (486 d.C.) y por Constantino el Grande. Estas ordenanzas provocaron los siguientes cambios:

5 Cicerón, M. T., Topica, 10, 44.

6 Cfr. D. 27, 7, 4, 3 (Ulpiano 36, ad edictum); y RicсовоNo, S., “'Stipulatio' ed 'instrumentum' nel diritto giustinianeo", Zeitschrift der Savigny-Stiftung, 43, 1922, 266.

7 GAYO, Institutionum, 3, 134. 
1. La abolición del sistema clásico de procedimiento (ordo iudiciorum privatorum), que fue reemplazado por la cognitio extraordinaria, el poder judicial estatal calificado.

2. Las prerrogativas del arbitrio del pretor sobre el juicio fueron descontinuadas.

3. La abolición de todas las fórmulas (342 d.C.); sin embargo, se siguieron utilizando según fuera necesario para indicar de manera concisa la naturaleza de la acción.

4. El uso, cada vez menor, de las formas solemnes del ius civile que termina en su abolición final. Esto ocurre en gran medida a través de la amplia autoridad del juez que, en cierto modo, se convierte en el heredero del pretor. En lugar de las fictiones empleadas por este último, sucedieron las praesumptiones o tacitae obligationes, introducidas en la práctica judicial. Por lo tanto, como evidencia existe una inversión completa con respecto al valor de los escritos (instrumenta), ya que estos últimos ahora se convierten en prueba absoluta, o al menos se consideran superiores a la declaración verbal de los testigos.

5. La influencia que la ética cristiana ejerció en este período sobre el derecho no debe pasarse por alto. Esto fue promovido por la ampliación de la Audiencia Episcopal. En un momento en que el Imperio se vio afectado por enfermedades y miserias, la ética cristiana actuó como un tónico para el corazón de esa gran organización universal, cuya paliza parecía haber cesado. Lo beneficioso de su reacción se demostró en el caso de los derechos personales, como la reforma matrimonial, la protección de mujeres y menores, la protección de los débiles contra los fuertes y, especialmente, de los esclavos. Esto disminuyó las dificultades resultantes de las concepciones individualistas paganas en todos los asuntos, teniendo en cuenta el bienestar general de la comunidad. Favoreció las donaciones que el derecho romano había mal visto, reprimió las prácticas legales fraudulentas y todas las formas de violencia privada. Sobre todo, permitió equidad para tener un alcance de acción más amplio y humano, por motivos éticos y sentimentales, y por un sentido de piedad y hermandad humana ${ }^{8}$.

Estos conceptos eran innegables, y en la unificación gradual de los tres elementos jurídicos enumerados anteriormente (ius civile, ius gentium, ius honorarium) el derecho dejó atrás:

1. Todos los institutos, principios, formas y precedentes del ius civile que fueron superados por el ius honorarium.

2. Un gran número de institutos y reglas creados por el pretor, ya sea para operar en contra o para apoyar el ius civile. Tales fueron la in integrum restitutio y la missio in possessionem.

Permanecieron, en cambio:

1. Los institutos del ius gentium y los elementos básicos del ius honorarium, que se utilizaron en lugar de elementos o institutos similares propios del ius civile, 
aunque en algunos casos el elemento más nuevo se incorporó a lo que sobrevivió del ius civile.

2. Y en este desarrollo del derecho, naturalmente, tienen el primer lugar ciertos conceptos maravillosos e importantes de la jurisprudencia romana, a saber, el elemento de la intención en los testamentos y en los otros negocios, los elementos de la causa (causa) y el acuerdo (conventio) en los contratos.

Sin embargo, los anteriores conceptos de intención, causa, etc. ya estaban implícitos en los negocios formales bajo el ius civile, y el pretor solo los trajo al foro en su administración equitativa de la justicia. Así, la equidad asumió la forma de la ley y fue dominada por la ética cristiana.

Cabe señalar que, con cambios tan profundos que tienen lugar espontáneamente, ya que ni las escuelas de derecho ni las legislaturas tuvieron parte en los mismos, el material complejo, aunque cuidadosamente subdividido y elaborado por los romanos, se convirtió en una masa caótica de institutos y precedentes en las manos de los practicantes bizantinos.

Los remedios de varios emperadores bizantinos para reparar esto no sirvieron de nada. El derecho romano parecía que sería destruido por su superabundancia de reglas y remedios. Justiniano lamenta continuamente que el derecho anterior a su tiempo fuera confusum, perturbatum, y describe su estado con los verbos "vacillare", "variare"9 y habla de las continuas "varietates" y "ambiguitates". Lo que él dice era verdad.

$\mathrm{Su}$ trabajo fue exitoso en lograr cierto orden en el derecho y en clasificar el material bajo importantes géneros.

Esto lo hizo Justiniano con abundante apoyo en ciertas fuentes genuinas que en ese momento estaban en uso por las escuelas de derecho en el Este (como lo muestran los fragmentos sinaíticos), así como siguiendo los precedentes judiciales. La satisfacción y el orgullo del emperador por su logro se encuentran plenamente justificados.

En realidad, por lo tanto, lo que aparece como material nuevo en el trabajo de Justiniano lo es tan solo en la forma y no en la sustancia.

Una gran parte del ius civile había sido eliminada o reemplazada por un nuevo derecho en los tiempos clásicos gracias a la tarea del pretor. Esta parte trataba asuntos cuya regulación era ahora obsoleta (en términos económicos, sociales, políticos y personales). Por el contrario, las reglas del ius honorarium, en cuanto a su sustancia, y las del ius gentium permanecieron intactas. Incluso reemplazaron asuntos similares en el ius civile.

El ius gentium también absorbió la mayor parte del ius civile, pues con la desaparición de los requisitos formales de este último, sus reglas se fusionaron con las

9 Este verbo figura también en un texto revisado de la Fragmenta Vaticana 49; cfr. Riccobono, S., "Formazione del domma della trasmissibilità all'erede dei rapporti sotto condizione", Studi Perozzi, n. ${ }^{\circ} 1$, Palermo, $1925,367$. 
del ius gentium que prevaleció. La stipulatio es una excelente ilustración al respecto. En el ius civile era un acto solemne y verbal, pero ahora se convierte en una simple convención, escrita u oral, y se basa ahora en los contratos del ius gentium, de los cuales ya no se puede distinguir. También se ajusta al nudum pactum del ius honorarium, que ahora también da lugar a una causa de acción judicial, mientras que la regla del derecho civil era nudo pacto actio non nascitur. En sus premisas y efectos, ambas formas de contrato son ahora igualmente eficaces. Todos se convierten en actos motivados, formas que como tales han dejado de usarse. Todos los negotia se convierten en nada más que conventiones, lo que implica un motivo o causa. Ciertamente un gran cambio, pero una evolución más que una revolución, que se produjo gradualmente y a partir de cambios dentro del cuerpo del derecho y contemplados por él. Pedio había formulado bien el principio: conventionis nomen generale est ${ }^{10}$, en el sentido de que ese término técnico abarcaba todas las categorías de negociación, las solemnes del ius civile, el contractus del ius gentium, los pacta del ius honorarium $^{11}$.

El elemento general y común a todas estas formas de derecho ha sido reconocido como primordial, necesariamente provocó la evolución legal y borró todas las diferencias. Así, dentro del derecho romano surgió el principio: “Todo acuerdo crea una obligación"12.

El nuevo ius civile en tal sentido compilado constituye, por lo tanto, un cuerpo de los elementos más progresivos de todo el derecho -tanto naturales como dogmáticos-, como se ilustra en el caso de la conventio. El ius gentium y el ius honorarium prevalecieron sobre el ius civile; los dos elementos anteriores resultaron más adaptables a las vicisitudes de lo social, económico, espiritual y familiar, todas ellas bien diferenciadas por la jurisprudencia clásica.

Incluso el procedimiento civil ordinario del período clásico tuvo que ceder ante la cognitio extraordinaria, porque el alcance de este último procedimiento se ampliaba continuamente, tanto en Roma como en las provincias. Sin embargo, el cambio de un sistema de procedimiento a otro solo se logró gradualmente.

El proceso de unir, o más bien simplificar, el derecho fue el efecto inmediato de las causas antes mencionadas que funcionaron de manera similar para todos los institutos. Por lo tanto, se puede decir que el nuevo derecho es, en esencia, el mismo derecho romano cuyos diversos componentes han sido revisados, remodelados y generalmente simplificados.

En el curso de este cambio el principio básico sufrió un duro golpe. El sistema jurídico romano se había construido sobre la jurisprudencia antigua-clásica cuyos principios y reglas, tomados del ius civile, fueron elaborados con una lógica inflexi-

10 D. 2, 14, 1, 3, y el texto que sigue en el título tomado del libro IV del comentario de Ulpiano al Edicto.

11 La demostración de esta parte, en Riccobono, S., Letture londinesi (maggio 1924), “Diritto romano e diritto moderno”, Torino, Giappichelli, 1924.

12 Cfr. Riccobono, S., “'Stipulatio’ ed 'instrumentum’ nel diritto giustinianeo”, cit., 338-378. 
ble y reflejaban de manera espléndida la severa disciplina pública y privada de los romanos. Cuando el ius civile y el ius honorarium dejaron de cubrir el mismo terreno legal de forma independiente, este último invadió al primero; no solo las reglas, sino también los principios mismos del ius civile, o bien se abandonaron necesariamente o, cuando menos, perdieron su carácter general e inflexible.

El dogma jurídico tuvo que ser completamente reconstruido para las compilaciones de Justiniano. Esto habría requerido más tiempo y habilidad de la que poseían los compiladores, ya que las escuelas de derecho no habían preparado ningún terreno para ello.

Nuevas máximas legales, presunciones, acciones y subdivisiones jurídicas que reflejaron la nueva fase del derecho resultaron de la aplicación práctica de la máxima rebus ipsis dictantibus, más que de estudios teóricos. Fue solo después del primer milenio que los eruditos de Bolonia comenzaron a remodelar los principios en los que se basaría el nuevo derecho romano.

Los comentaristas italianos hasta Alciato (1550), que realizó la tarea que les dejó Justiniano, mostraron el verdadero carácter de la compilación y realmente establecieron los fundamentos del derecho moderno, que se extendió gradualmente por toda Europa ${ }^{13}$.

Justiniano había compilado las viejas reglas del derecho siguiendo las formas tal como aparecían en las obras de los juristas clásicos. Así, los tres elementos o ramas del derecho, ius civile, ius gentium y ius honorarium, se destacan en el Corpus Iuris, y los comentaristas los consideraron como si aún fueran fuentes distintas de las que se desarrolló el derecho.

El error se repitió y se hizo aún mayor en el siglo XIX cuando la escuela histórica analizó el Corpus Iuris siguiendo lo que se creía que era la pista dada por Gayo.

El trabajo de los glosadores y de los comentaristas fue ignorado o considerado incorrecto. Los textos fueron interpretados nuevamente y los institutos legales revisados para cumplir con sus puntos de vista. El error radica en que, al hacerlo, reconstruyeron el derecho romano clásico y no el del período del Corpus Iuris.

Ahora puedo aclarar este grave error al mostrar el método seguido por Justiniano para hacer la compilación comparándolo con la evolución que experimentó el derecho durante los siglos IV y v d.C., como se describe en las páginas anteriores ${ }^{14}$.

Justiniano no tenía la intención de revivir, ni podría haber revivido, el antiguo derecho con todas las subdivisiones obsoletas. En las nuevas leyes, las distinciones esenciales para el derecho clásico habían desaparecido.

Ejemplos: en el caso de legados (legata) en comparación con ciertos fideicomisos (fidei commissa), etc.; herencia (hereditas) vs. posesión (bonorum posses-

13 Cfr. Vinogradoff, P., Roman Law in Medieval Europe, London-New York, Harper \& Brothers, 1909.

14 Véase también Riccobono, S., “La fusione del 'ius civile' e del 'ius praetorium' in unico ordinamento", Archiv für Rechts und Wirtschaftsphilosophie, 16, 1922-23, 503-522. 
sio); título (dominium ex iure Quiritium) vs. in bonis habere; stipulatio acceptilatio vs. pacta; actiones vs. interdicta; actiones directae vs. utilis. Sin embargo, justifica mantener la terminología y las distinciones antiguas por dos razones, a las que podemos agregar una tercera de la siguiente manera:

1. Porque el derecho, tal como lo trataron los juristas, se había hecho breve y se había elaborado de manera formal, y porque la dificultad de separarlo completamente y simplificarlo era demasiado grande ${ }^{15}$.

2. Porque la fusión del derecho civil y el derecho pretorio, o, en general, la fusión de diferentes institutos que cubren el mismo punto, cada uno derivado de una rama diferente del derecho, habría confundido la mente jurídica romana entrenada en las formas como fue transmitido por generaciones. Por lo tanto, se consideró más conveniente y literario establecer el derecho como antes, y luego observar los cambios sucesivos. Este método se aplicó directa y específicamente a las instituciones, pero también se siguió con bastante regularidad en el Digesto ${ }^{16}$.

3. Por último, debido a que el intento realizado originalmente por los comisarios legislativos en la primera parte del Digesto para consolidar los diversos institutos antiguos que se habían unificado, tuvo que abandonarse debido a la dificultad de ejecución y, además, la urgencia de completar el trabajo de compilación no permitió suficiente tiempo para esto ${ }^{17}$.

El gran número de interpolaciones en el Digesto muestra mediante cuáles recursos los compiladores llegaron a obtener los resultados más prácticos en el menor tiempo, de la siguiente manera:

1. Los pasajes tomados de las obras de los juristas recibieron interpolaciones, o fueron cambiados o abreviados según era necesario ${ }^{18}$.

2. Las adiciones (addictiones) se notan fácilmente por su lenguaje y estilo, aparte de sus contenidos, que reflejan el derecho vigente. Pero el asunto contenido en todas o la mayor parte de las adiciones fue tomado de casos clásicos. Estos casos generalmente muestran la aplicación del ius honorarium, la consolidación de varios institutos, cada uno de una rama diferente del derecho, o son una selección de una de varias decisiones sobre el tema, independientemente de en cuál de los tres elementos jurídicos se basan. A veces los compiladores seleccionaron la teoría más progresista expuesta por los juristas, o encarnaban interpretaciones judiciales puras sobre decisiones basadas en rescriptos imperiales. Incluso utilizaron ideas fundamentales para corregir la lentitud en materia procesal y formal. Algunas de las adiciones realmente

15 Justiniano, Constitutio Tanta, $\S 14$.

16 Ver Justiniano, Institutionum, 2, 20, 3.

17 Cfr. Riccobono, S., "La fusione del 'ius civile' e del 'ius praetorium' in unico ordinamento", cit., 518.

18 Sobre el punto véase Gradenwitz, O., Interpolationen in den Pandekten, Berlin, Weidmann, 1887; los trabajos fundamentales de Lenel: Lenel, O., Das Edictum Perpetuum, 2. a ed., Leipzig, 1907, 1883, y Lenel, O., Palingenesia iuris civilis, vols. I-II, Leipzig, 1880; y el valioso artículo de Buckland, W. W., "Interpolations in the Digest", Yale Law Journal, 33, 1924, 343. 
constituyeron derecho positivo, en la medida en que las decisiones sobre casos concretos establecidos en las respuestas formales (responsa) lograron así una aplicación general mediante el uso de varias hipótesis, aunque a veces contradictorias, que se introdujeron mediante breves cláusulas que comenzaban "a menos que" (nisi...) o por distinciones refinadas (si de hecho... si en verdad -si quidem-si vero).

3.Con el mismo fin, los compiladores omitieron partes de pasajes relacionados con puntos en disputa, diferencias debidas a distintos elementos jurídicos (ius civile, etc.), en los que las decisiones se basaban en normas del derecho civil con analogías y desarrollos que se habían hecho obsoletos. Estas omisiones o supresiones de ciertos textos a veces son difíciles de probar, pero cobran una importancia extraordinaria para determinar cuál era el derecho clásico. Hasta ahora he encontrado alrededor de una docena de casos de omisiones importantes ${ }^{19}$. En los fragmentos tomados de obras clásicas íntegras, como las quaestiones, el tema es a veces, particularmente en la introducción, tratado in extenso, y luego de repente hay abreviatura o silencio. Un ejemplo de este tipo también se encuentra en el Fragmento Vaticano 50.

4. Los cambios en el texto son tan evidentes como las adiciones. Las interpolaciones que se relacionan con la nueva terminología en los institutos de derecho privado son casi todas reconocidas. La nueva terminología nos permite observar qué reglas de la ley se han vuelto obsoletas o se han modificado, y qué institutos se han consolidado.

5. La lista de pasajes que se han condensado es numerosa e importante. De ciertos títulos, que se trataron completamente en las fuentes, los compiladores con frecuencia solo hicieron un resumen, pero conservaron frases y fragmentos del original clásico en su compilación forzada. Con frecuencia, el resumen en cuestión cubre varios textos del mismo jurista, o de diferentes juristas.

6. Los propios compiladores redactaron una gran cantidad de textos breves, que se encuentran dispersos en el Digesto y el Codex. Contienen maxima, o decisiones del nuevo derecho, y representan la síntesis de los distintos elementos jurídicos consolidados, la forma final del derecho tal como se desarrolló durante los siglos anteriores. Estos pasajes, que son numerosos y distintos, se destacan prominentemente en la compilación, y se ubican principalmente al comienzo de los diversos títulos. Así, los fragmentos 1 y 2 en D. 37, 1 señalan la fusión perfecta entre hereditas y bonorum possessio, pero tienen títulos distintos y aparecen por separado en el curso de la obra.

Es superfluo agregar que, si bien generalmente son los textos más largos los que indican interpolaciones, estas también se encuentran con frecuencia en los textos más cortos. Pero debe notarse particularmente que es el derecho de la época de Justiniano el que está incorporado en los pasajes interpolados, así como en otras partes

19 Un ejemplo paradigmático se puede ver en D. 8, 1, 4, con ilustración en Riccobono, S., “'Dies” e 'condicio' nella costituzione delle servitù su fondi italici e su fondi provinciali”, Revue d'histoire du droit, vol. III, 1922, 335. 
del texto. Los comisarios generalmente conocían el derecho vigente y entendieron cómo se había desarrollado y las causas responsables de los cambios que sufrió. En ningún lugar y por ninguna doctrina confiaron en los maestros o las escuelas orientales. Se dieron cuenta de que su tarea era solo codificar el derecho existente, ya que se había consolidado y reformado en la práctica judicial.

En el Imperio occidental, los textos visigodos muestran que el derecho había experimentado un proceso similar de evolución y las interpolaciones son con frecuencia las mismas. Brevemente, los comisarios sintieron que habían cumplido su tarea al emplear los métodos y recursos descritos anteriormente para adaptar lo que era mejor en el material antiguo para el derecho de su época. Al hacerlo, lograron reducir a una vigésima parte de su volumen total tres millones de líneas contenidas en las obras de los juristas. Al leer detenidamente y hacer extractos lograron producir una obra que contiene los elementos esenciales del nuevo derecho.

La mejor comprobación de lo anterior es la prueba analítica a la que el código se sometió con éxito por mano de los glosadores y los comentaristas italianos que fueron los primeros intérpretes reales del Corpus Iuris. Esto, sin embargo, no implica que Justiniano y sus colaboradores hayan realizado un trabajo sin imperfecciones. Considerado como un código, era voluminoso, su estructura era arcaica y contenía numerosas contradicciones. Sin embargo, sirvió como una valiosa antología de información histórica, a la que los autores atribuyeron gran importancia. Su valor general se muestra mejor por su influencia civilizadora en la época medieval y moderna.

La evolución del derecho romano, como se describió anteriormente, siguió un curso regular que se ve a partir de afirmaciones explícitas en el Corpus Iuris y de un análisis de su contenido. Las contrapartes históricas confirman lo mismo. De hecho, los mismos procesos simplificadores que tuvieron lugar en Roma fueron, en cierto sentido, repetidos en Inglaterra, donde la distinción entre los tribunales de derecho consuetudinario y los tribunales de equidad era análoga a la existente entre el derecho civil romano y la equidad, stricta iudicia e iudicia bonae fidei.

Del mismo modo, incluso en el derecho inglés, la clara distinción entre los dos elementos judiciales se atenuó gradualmente hasta que las Leyes de la Judicatura de 1873-1875 provocaron la fusión completa de la equidad y la ley. La equidad se convierte naturalmente en el elemento predominante, como se muestra en la siguiente cláusula de la sección 25 de la Ley de 1873:

En general, en todos los asuntos no mencionados anteriormente, en particular, en los que exista algún conflicto o variación entre las reglas de equidad y las reglas del derecho consuetudinario, con referencia al mismo asunto, prevalecerán las reglas de la equidad.

Por lo tanto, existe una analogía sorprendente en la evolución de los sistemas jurídicos inglés y romano. Los emperadores Constantino y Licinio, en 314 d.C., también 
confirmaron la prevalencia de la equidad sobre el derecho estricto con la siguiente afirmación solemne:

C. 3, 1, 8: Placuit in omnibus praecipuam esse iustitiae aequitatisque quam stricti iuris rationem [En todas las causas, la razón de justicia y equidad sea preferible a la del derecho estricto].

Que la ley de Constantino haya sido sometida a una generalización (in omnibus rebus) por los compiladores del Código (Codex) de Justiniano, no tiene importancia. Esto puede haberse referido originalmente a casos de esclavos liberados de acuerdo con el derecho civil, como cree Kruger. Pero, en cualquier caso, es cierto:

(a) Que durante los siglos IV y v, la prevalencia de la equidad sobre la ley se había arraigado tanto que los compiladores formularon e insertaron en el Digesto la siguiente máxima en el título sobre las reglas del derecho, en D. 50, 17, 90 (Paulo 15 quaestionum): in omnibus quidem, maxime tamen in iure, aequitas spectanda est [en todas las cosas, y en el derecho sobre todo, debe contemplarse la equidad].

(b) Que el predominio de la equidad sobre la ley surge de una evolución orgánica dentro del derecho romano, y es erróneo atribuirlo a la influencia de la filosofía griega o incluso considerarlo como lo hizo Pringsheim ${ }^{20}$.

Celso definió el derecho, como se dijo, como ars aequi et boni, y todos los esfuerzos del Pretor tendieron a mitigar el rigor y las injusticias del derecho civil, incluso en decisiones basadas en el derecho estricto.

Con la desaparición del Pretor y con la fórmula despojada de todo valor jurídico, la autoridad del juez se amplió correspondientemente en todos los casos, ya que heredó y asumió los poderes y la misión del Pretor. Sus concesiones equitativas, naturalmente, ahora tenían un sesgo claramente cristiano.

En Inglaterra, las Leyes de la Judicatura de 1873-1875 establecieron un código de procedimiento civil en el que los jueces tenían grandes poderes discrecionales y, en consecuencia, como en el procedimiento extraordinario romano, disminuyó la importancia de los distintos formularios para las acciones ${ }^{21}$.

Volviendo a nuestro tema principal, después de esta breve exposición, soy lo suficientemente valiente como para afirmar que se ha explicado debidamente el cambio rígido que ocurrió en el derecho romano de Constantino a Justiniano.

Realmente es solo la simplificación de las reglas de derecho originalmente muy complejas que se formaron en Roma debido a eventos y condiciones peculiares e

20 Pringsheim, F., “'Ius aequum' und 'ius strictum””, Zeitschrift der Savigny-Stiftung, 42, 1922, 643.

21 Cfr. Maitland, F. W., Equity: Also The Forms of Action at Common Law, Cambridge, University Press, 1920. 
históricos, reglas que ya no podían existir cuando desaparecieron las condiciones que las habían originado.

Esta explicación, además de resolver los diversos problemas relacionados con la evolución del derecho romano, sirve directamente como base para la crítica e interpretación del Corpus Iuris, así como de los institutos de todo el derecho moderno que se basa en el derecho romano.

Este artículo no permite dar prueba de mis afirmaciones, que, sin embargo, se pueden encontrar en mis otros trabajos. Solo puedo afirmar que se basan en investigaciones especiales entre los varios institutos.

Sin embargo, debo señalar que la explicación histórica como se describe anteriormente, generalmente fue seguida por los principales historiadores del derecho, comenzando con Savigny y continuada por Karlowa y Voigt; por Muirhead en Inglaterra y por Charles Phineas Sherman en Estados Unidos ${ }^{22}$. Pero, como se puede ver, estos autores basaron sus conclusiones completamente en algunos pasajes de las constituciones de Justiniano y en otros pasajes que, desde las Glosas, ya habían aparecido en el siglo XVI como interpolaciones.

Por lo tanto, cuando se creía que el Digesto, debido a las numerosas interpolaciones, había sido más obra de Justiniano que de los juristas romanos, la explicación anterior del cambio legal fue considerada por ellos como sin valor. Los académicos, en su búsqueda de una solución mejor y más recóndita, que también entraría en más detalles, como ocurre a menudo, pasaron por alto el elemento más importante y los puntos decisivos. Así, en palabras de Dante, vagaron...

... a través de un bosque oscuro en el que se había perdido el camino correcto.

\section{Referencias}

Aristóteles, Ethica Nicomachea.

Bryce, J., Studies in History and Jurisprudence, Oxford University Press, vol. I,1901 .

Buckland, W. W., "Interpolations in the Digest", Yale Law Journal, 33, 1924.

Cicerón, M. T., De legibus.

Cicerón, M. T., Topica.

GAYO, Institutionum.

22 Sherman, Ch. Ph., Roman Law in the Modern World, vol. I, Boston, Book Company, 1917, § 122, 105. 
Gradenwitz, O., Interpolationen in den Pandekten, Berlin, Weidmann, 1887.

Lenel, O., Palingenesia iuris civilis, vols. I-II, Leipzig, 1880.

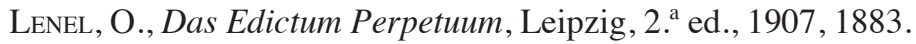

Justiniano, Constitutio Tanta.

Maitland, F. W., Equity: Also The Forms of Action at Common Law, Cambridge, University Press, 1920.

Pringsheim, F., “'Ius aequum' und 'ius strictum”, Zeitschrift der Savigny-Stiftung, $42,1922$.

Riccoвono, S., "Cristianesimo e diritto privato", Rivista di diritto civile, vol. 3, 1911.

Riccobono, S., “'Dies' e 'condicio' nella costituzione delle servitù su fondi italici e su fondi provinciali", Revue d'histoire du droit, vol. III, 1922.

Riccoвono, S., “La fusione del 'ius civile' e del 'ius praetorium' in unico ordinamento", Archiv für Rechts- und Wirtschaftsphilosophie, 16, 1922-23.

Riccoвono, S., “'Stipulatio' ed 'instrumentum' nel diritto giustinianeo”, Zeitschrift der Savigny-Stiftung, 43, 1922.

Riccobono, S., Letture londinesi (maggio 1924), “Diritto romano e diritto moderno”, Torino, Giappichelli, 1924.

Riccobono, S., "Formazione del domma della trasmissibilità all'erede dei rapporti sotto condizione", Studi Perozzi, n. ${ }^{\circ}$ 1, Palermo, 1925.

Sherman, Ch. Ph., Roman Law in the Modern World, vol. I, Boston, Book Company, 1917.

Vinogradoff, P., Roman Law in Medieval Europe, London-New York, Harper \& Brothers, 1909. 